\title{
Maatiais- ja yorkshiresikojen lihaprosentin, kasvunopeuden ja lihan laadun perinnölliset tunnusluvut
}

\author{
Marja-Liisa Sevón-Aimonen ja Asko Mäki-Tanila \\ MTT, 31600 Jokioinen, etunimi.sukunimi@mtt.fi
}

\section{Tiivistelmä}

Sikojen tärkeimmät valintatavoitteet kantakokeessa ovat olleet kasvunopeus, rehunmuuntosuhde, liha\% ja kyljysselästä mitattu punaisen lihan laatu (loppu-pH ja väri). Punaisen lihan laatu on epäsuotuisasti korreloitunut muihin valittaviin ominaisuuksiin, ja sen osalta tavoitteena on aikaisemmin ollut pitää laatu ennallaan muita ominaisuuksia parannettaessa. Kyljysselän lihan laadun seuranta ei välttämättä takaa sian muiden lihasten laadun säilymistä muuttumattomana. Siksi kinkun eri lihasten laatua selvitettiin vuonna 1999 tuhannen sian otoksella. Tulosten perusteella sisäpaistin laatu (semimembranosus) päätettiin ottaa mukaan kantakoeindeksiin vuonna 2000. Sekä kyljyksen että kinkun laadun suhteen tavoitteeksi otettiin loppu-pH-arvon nostaminen ja värin tummentaminen. Koska lihan laadun periytymisasteet ovat matalia, olivat vuoden 1999 pienestä aineistosta estimoitujen geneettisten korrelaatioiden keskivirheet suuria. Tässä tutkimuksessa oli tavoitteena laskea luotettavat estimaatit kansalliseen sikojen jalostusarvostelulaskentaan käyttäen hyväksi kantakoetoiminnassa vuodesta 2000 vuoden 2003 loppuun asti kertynyttä suurempaa aineistoa

Aineisto saatiin Suomen Kotieläinjalostus Osuuskunnalta (SKJO) ja se sisälsi havainnot yhteensä 7685 yorkshire- ja 7467 maatiaissiasta. Näille liitettiin sukulaisuustiedot. Tutkitut ominaisuudet olivat keskimääräinen kasvunopeus $30 \mathrm{~kg}-100 \mathrm{~kg}$, lihaprosentti, lihan väri ( $\mathrm{L}^{*}$ vaaleus, a* punaisuus ja b* keltaisuus) ja loppu-pH mitattuna sekä kyljysselästä että kinkun sisäpaistista. Rodut analysoitiin erikseen monenominaisuuden eläinmallilla käyttäen DMU-ohjelmistoa. Laatuominaisuuksien tilastollisessa mallissa oli kiinteinä tekijöinä sukupuoli, ikä kokeen alussa, viive teurastuksesta leikkuuseen ja satunnaisina tekijöinä eläimen additiivinen geneettinen vaikutus, pahnue, teurastuserä (samalta asemalta samana päivänä teurastamoon lähetettyt siat) ja satunnainen jäännöstermi. Kasvunopeuden ja liha-\% mallissa malli oli muutoin samanlainen, mutta teurastuserän sijasta oli kasvatuserä kiinteänä tekijänä ja viive oli jätetty pois.

Periytymisasteet vaihtelivat 0,33-0,39 kasvunopeudessa, 0,39-0,47 lihaprosentissa, 0,12-0,20 pH:ssa, 0,10 - 0,32 vaaleudessa ja 0,26 - 0,43 punaisuudessa. Geneettiset korrelaatiot kasvunopeuden ja lihanlaatuominaisuuksien välillä olivat useimmissa tapauksissa matalia (alle 0,15). Sen sijaan geneettiset korrelaatiot lihaprosentin ja lihan laadun (erityisesti sisäpaistin laadun) välillä olivat korkeampia ja epäsuotuisia. Kyljysselästä ja sisäpaistista mitattujen samojen lihanlaatuominaisuuksien geneettiset korrelaatiot olivat korkeita, mutta kuitenkin selvästi alle yhden, eli pelkän kyljysselän sisällyttäminen valintaohjelmaan ei takaa hyvää kinkun laatua. Johtuen epäsuotuisasta korrelaatiosta taloudellisesti tärkeän lihaprosentin ja lihan laadun välillä, on lihan laatu säilytettävä jalostustavoitteissa. Korrelaatio ei kuitenkaan ole niin voimakas, etteikö oikealla tavoitteiden asettelulla liha-\% voida parantaa laadun siitä kärsimättä.

Tässä tutkimuksessa estimoituja perinnöllisiä tunnuslukuja käytetään hyväksi kansallisessa sikojen jalostusarvojen laskennassa. Lihan laadun valinnan tehostamisen jälkeen lasketut geneettiset trendit osoittavat, että lihan laatu on muuttunut toivottuun suuntaan.

Asiasanat: sika, lihan laatu, perinnölliset tunnusluvut 


\section{Johdanto}

Sian punaisen lihan laatu (väri, pH, valuma) vaikuttaa kuluttajien ostopäätöksiin ja lihan teknologiseen laatuun varsinkin kokolihatuotteita valmistettaessa. Nykyinen trendi, jossa kuluttajat haluavat välttää lisäaineita (suolaa, fosfaatteja), nostaa lihan laadun merkitystä entisestään. Lihan väri ja pH riippuu paljon siitä, minkä tyyppinen lihas on kyseessä. Ongelmia laadun suhteen ilmenee helpoimmin suurissa, vaaleissa lihaksissa, joiden loppu-pH laskee alle optimin $(5,6-5,8)$ ja värimittarilla mitattu vaaleutta kuvaava $L^{*}$ arvo nousee yli optimin (48-54).

Tärkeimmät valintatavoitteet kantakokeessa mitattavissa lihasian ominaisuuksissa ovat olleet kasvunopeus, rehunmuuntosuhde, liha-\% ja kyljysselästä (longissimus) mitattu punaisen lihan laatu (loppu-pH ja vaaleus). Punaisen lihan laatu on epäsuotuisasti korreloitunut muihin valittaviin ominaisuuksiin, mikä merkitsee sitä, että laatu pyrkii heikkenemään muita ominaisuuksia valittaessa, ellei sitä oteta huomioon (Hovenier ym. 1995, Knapp ym. 1997). Laatua kuvaavat pH ja L* ovat optimiominaisuuksia, joissa sekä liian korkeat että matalat arvot merkitsevät ongelmia laadussa (Kauffman ym. 1993, Joo ym. 1995). Laadun osalta tavoitteena oli aikaisemmin pitää laatu ennallaan muita ominaisuuksia parannettaessa.

Valinta pelkän ulkofileen laadun perusteella ei välttämättä riitä pitämään kinkun laatua hyvänä. Siksi kinkun eri lihasten laatua selvitettiin vuonna 1999 tuhannen sian otoksella. Tulosten perusteella sisäpaistista (semimembranosus) mitattu kinkun laatu päätettiin ottaa mukaan kantakoeindeksiin vuonna 2000. Sekä kyljysselän että kinkun laadun suhteen tilapäiseksi tavoitteeksi otettiin sen hetkisen tason säilyttämisen sijasta loppu-pH-arvon nostaminen ja värin tummentaminen. Koska lihan laadun periytymisasteet ovat matalia, olivat vuoden 1999 pienestä aineistosta estimoitujen geneettisten korrelaatioiden keskivirheet suuria. Tässä tutkimuksessa oli tavoitteena laskea luotettavat estimaatit kansalliseen sikojen jalostusarvostelulaskentaan käyttäen hyväksi kantakoetoiminnassa vuodesta 2000 vuoden 2003 loppuun mennessä kertynyttä aineistoa.

\section{Aineisto ja menetelmät}

Aineisto saatiin Suomen Kotieläinjalostus Osuuskunnalta (SKJO) ja se sisälsi havainnot yhteensä 7467 maatiais- ja 7685 yorkshiresiasta. Näille liitettiin sukulaisuustiedot (taulukko 1).

Taulukko 1. Aineiston rakenne

\begin{tabular}{lll}
\hline & Maatiainen & Yorkshire \\
\hline Eläimiä, joilla havainto & 7685 & 7467 \\
-Puolisisarryhmiä & 749 & 706 \\
-Täyssisarryhmiä & 2701 & 2605 \\
$\begin{array}{l}\text { Sukulaiseläimiä, } \\
\text { joilla ei omaa tulosta }\end{array}$ & 7316 & 6566 \\
\hline
\end{tabular}

Tutkitut ominaisuudet olivat kasvunopeus (painovälillä 30-100 kg), lihaprosentti, lihan väri eli (CIE L*a*b* standard 1971) L* vaaleus, a* punaisuus ja b* keltaisuus ja loppu-pH mitattuna sekä kyljysselän ulkofileestä (Longissimus) että kinkun sisäpaistista (Semimembranosus). Rodut analysoitiin erikseen monenominaisuuden eläinmallilla käyttäen DMU-ohjelmistoa (Madsen ja Jensen 2000).

Laatuominaisuuksien tilastollisessa mallissa oli kiinteinä tekijöinä sukupuoli, ikä kokeen alussa, viive teurastuksesta leikkuuseen ja satunnaisina tekijöinä eläimen additiivinen geneettinen vaikutus, pahnue, teurastuserä (samalta asemalta samana päivänä teurastamoon lähetettyt siat) ja satunnainen jäännöstermi. Kasvunopeuden ja liha-\% mallissa teurastuserän sijasta oli kasvatuserä kiinteänä tekijänä ja viive oli jätetty pois. 


\section{Tulokset ja niiden tarkastelu}

Rotujen välillä ei ollut suuria eroja keskiarvoissa tai hajonnoissa (taulukko 2). Maatiaissiat kasvoivat hieman nopeammin ja niiden lihan laatua kuvaavat mitan olivat jonkin verran huonompia kuin yorkshirella. Tutkittujen lihasten välillä oli suuret erot. Sisäpaisti on selvästi vaaleampi ( $L^{*}$ yli 61,0$)$ kuin ulkofile $(55,0-55,6)$. Sen sijaan sisäpaistin loppu-pH on keskimäärin hieman korkeampi $(5,6)$ kuin ulkofileen.

Taulukko 2. Tutkittujen ominaisuuksien keskiarvot, hajonnat (S.D.), minimit (min) ja maksimit (max) roduittain.

\begin{tabular}{|c|c|c|c|c|c|c|c|c|}
\hline & \multicolumn{4}{|c|}{ Maatiainen } & $\begin{array}{l}\text { Yorkshire } \\
\text { Keskiarvo }\end{array}$ & \multicolumn{2}{|c|}{ Yorkshire } & $\max$ \\
\hline Kasvu, g/d & 1043 & 94 & 634 & 1430 & 1019 & 98 & 624 & 1418 \\
\hline Liha-\% & 63,91 & 2,20 & 55,6 & 71,9 & 64,13 & 1,76 & 55,8 & 71,2 \\
\hline Kyljys & & & & & & & & \\
\hline$p H_{u}($ loppu-pH) & 5,54 & 0,15 & 5,01 & 6,50 & 5,57 & 0,14 & 5,05 & 6,50 \\
\hline$L^{*}$ (vaaleus) & 55,63 & 3,15 & 38,8 & 68,7 & 54,97 & 3,16 & 40,6 & 64,7 \\
\hline$a^{*}$ (punaisuus) & 7,41 & 1,28 & 3,0 & 17,3 & 6,76 & 1,20 & 1,2 & 12,9 \\
\hline b* (keltaisuus) & 3,30 & 1,18 & 0,1 & 12,5 & 2,95 & 1,14 & 0,1 & 15,5 \\
\hline Kinkku & & & & & & & & \\
\hline$p H_{u}($ loppu-pH) & 5,60 & 0,14 & 5,18 & 6,55 & 5,62 & 0,13 & 4,66 & 6,55 \\
\hline$L^{*}$ (vaaleus) & 61,08 & 3,64 & 44,2 & 76,0 & 61,02 & 3,62 & 46,6 & 72,4 \\
\hline$a^{*}$ (punaisuus) & 6,86 & 1,54 & 2,0 & 12,2 & 6,54 & 1,50 & 1,6 & 12,2 \\
\hline b* (keltaisuus) & 4,84 & 1,39 & 0,3 & 10,8 & 4,71 & 1,34 & 0,1 & 11,0 \\
\hline
\end{tabular}

Ominaisuuksien periytymisasteet ja korrelaatiot on esitetty taulukossa 3 (maatiainen) ja 4 (yorkshire). Periytymisasteet vaihtelivat 0,28 ja 0,30 välillä kasvunopeudessa, 0,39 ja 0,47 välillä lihaprosentissa, 0,12 ja 0,20 välillä $p H$ :ssa sekä 0,10 ja 0,34 välillä vaaleudessa. Lihan punaisuutta kuvaava $a^{*}$-arvon periytymisaste oli selvästi korkeampi kuin muiden laatuomisuuksien vaihdellen 0,25 ja 0,43 välillä. Myös aikaisemmissa tutkimuksissa on todettu laatuominaisuuksien periytymisasteiden olevan matalampia kuin kasvun tai ruhon lihakkuuden (Knapp ym. 1997) ja punaisuuden periytyvän voimakkaammin kuin muiden laatuominaisuuksien (Andersen ja Pedersen 1999).

Geneettiset korrelaatiot kasvunopeuden ja lihanlaatuominaisuuksien välillä olivat useimmissa tapauksissa matalia. Sen sijaan geneettiset korrelaatiot lihaprosentin ja lihan laadun (erityisesti sisäpaistin laadun) välillä olivat korkeampia ja epäsuotuisia. Eri lihaksesta mitattujen samojen mittojen korrelaatiot olivat korkeita, mutta geneettiset korrelaatiot olivat kuitenkin selvästi alle yhden. Fenotyyppiset korrelaatiot laadun ja muiden tutkittujen ominaisuuksien välillä olivat matalia. 
Taulukko 3. Maatiaisten periytymisasteet lävistäjällä, geneettiset korrelaatiot yläkolmiossa ja fenotyyppiset alakolmiossa.

\begin{tabular}{|c|c|c|c|c|c|c|c|c|c|c|}
\hline & kasvu g/pv & liha-\% & $\begin{array}{l}\text { Kyljys } \\
\text { pH }\end{array}$ & kyljys L* & kyljys $a^{\star}$ & kyljys b* & kinkku pH & kinkku $L^{*}$ & kinkku $a^{*}$ & kinkku b* \\
\hline kasvu g/pv & 0,33 & 0,01 & 0,05 & 0,03 & 0,01 & 0,01 & 0,15 & 0,10 & $-0,14$ & $-0,22$ \\
\hline liha-\% & $-0,19$ & 0,39 & $-0,31$ & 0,33 & $-0,02$ & 0,23 & $-0,40$ & 0,26 & $-0,17$ & $-0,10$ \\
\hline kyljys pH & $-0,06$ & $-0,06$ & 0,12 & $-0,70$ & $-0,23$ & $-0,54$ & 0,88 & $-0,28$ & 0,06 & 0,01 \\
\hline kyljys L* & 0,05 & 0,09 & $-0,59$ & 0,17 & $-0,39$ & 0,38 & $-0,66$ & 0,65 & $-0,41$ & $-0,33$ \\
\hline kyljys $a^{*}$ & 0,00 & 0,01 & $-0,21$ & 0,07 & 0,43 & 0,75 & $-0,20$ & $-0,33$ & 0,68 & 0,72 \\
\hline kyljys $b^{*}$ & 0,01 & 0,07 & $-0,35$ & 0,56 & 0,57 & 0,18 & $-0,53$ & 0,07 & 0,29 & 0,55 \\
\hline kinkku pH & $-0,03$ & $-0,08$ & 0,58 & $-0,38$ & $-0,12$ & $-0,23$ & 0,12 & $-0,37$ & 0,19 & 0,16 \\
\hline kinkku L* & 0,05 & 0,05 & $-0,21$ & 0,33 & $-0,07$ & 0,14 & $-0,25$ & 0,10 & $-0,79$ & $-0,57$ \\
\hline kinkku $a^{*}$ & $-0,04$ & $-0,06$ & $-0,04$ & $-0,07$ & 0,04 & 0,12 & $-0,01$ & $-0,38$ & 0,33 & 0,86 \\
\hline kinkku $b^{*}$ & 0,00 & $-0,01$ & 0,16 & 0,14 & 0,19 & 0,22 & $-0,16$ & 0,34 & 0,47 & 0,09 \\
\hline
\end{tabular}

Taulukko 4. Yorkshiren periytymisasteet lävistäjällä, geneettiset korrelaatiot yläkolmiossa ja fenotyyppiset alakolmiossa.

\begin{tabular}{|c|c|c|c|c|c|c|c|c|c|c|}
\hline & kasvu g/pv & liha- $\%$ & $\begin{array}{c}\text { kyljys } \\
\text { pH }\end{array}$ & Kyljys L* & kyljys $a^{\star}$ & kyljys b* & kinkku pH & kinkku L* & kinkku $a^{*}$ & kinkku b* \\
\hline kasvu g/pv & 0,39 & $-0,20$ & $-0,05$ & 0,12 & 0,03 & 0,09 & 0,03 & 0,01 & $-0,09$ & $-0,27$ \\
\hline liha-\% & $-0,13$ & 0,47 & $-0,29$ & 0,22 & $-0,08$ & 0,15 & $-0,40$ & 0,21 & $-0,24$ & 0,24 \\
\hline kyljys pH & $-0,05$ & $-0,12$ & 0,20 & $-0,84$ & $-0,31$ & $-0,83$ & 0,92 & $-0,28$ & $-0,17$ & $-0,46$ \\
\hline kyljys L* & 0,07 & 0,16 & $-0,56$ & 0,32 & $-0,17$ & 0,75 & $-0,82$ & 0,68 & $-0,16$ & 0,38 \\
\hline kyljys $a^{*}$ & 0,01 & 0,00 & $-0,21$ & 0,05 & 0,42 & 0,46 & $-0,25$ & $-0,36$ & 0,66 & 0,45 \\
\hline kyljys b* & 0,03 & 0,01 & $-0,35$ & 0,56 & 0,49 & 0,20 & $-0,82$ & 0,31 & 0,31 & 0,71 \\
\hline kinkku pH & $-0,01$ & $-0,16$ & 0,58 & $-0,39$ & $-0,14$ & $-0,26$ & 0,19 & $-0,52$ & $-0,09$ & $-0,54$ \\
\hline kinkku L* & 0,05 & 0,07 & $-0,16$ & 0,32 & $-0,09$ & 0,11 & $-0,04$ & 0,10 & $-0,62$ & 0,08 \\
\hline kinkku $a^{*}$ & $-0,03$ & $-0,07$ & $-0,07$ & 0,07 & 0,40 & 0,13 & 0,14 & $-0,37$ & 0,25 & 0,68 \\
\hline kinkku b* & 0,01 & 0,02 & $-0,14$ & 0,14 & 0,18 & 0,24 & $-0,25$ & 0,38 & 0,44 & 0,11 \\
\hline
\end{tabular}


Laatuominaisuuksien geneettisistä trendeistä näkyy (kuvio 1 ja 2), että tehostettu lihan laadun valinta on nostanut eli muuttanut toivottuun suuntaan loppu-pH-arvoja ja alentanut $\mathrm{L}^{*}$-arvoja eli tummentanut lihan väriä.

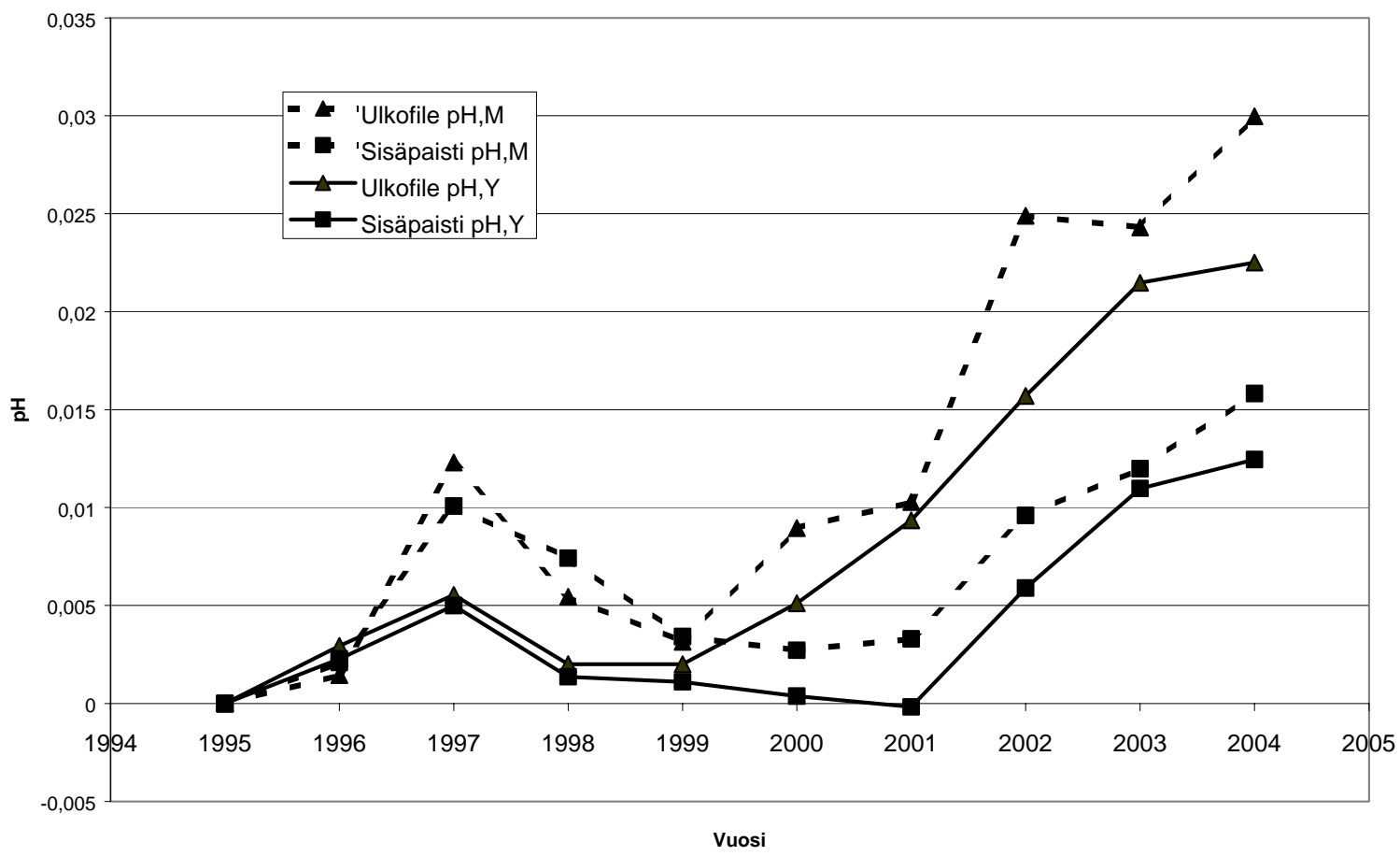

Kuvio 1. Loppu-pH arvojen geneettiset trendit maatiaisilla (M) ja yorkshirella (Y).

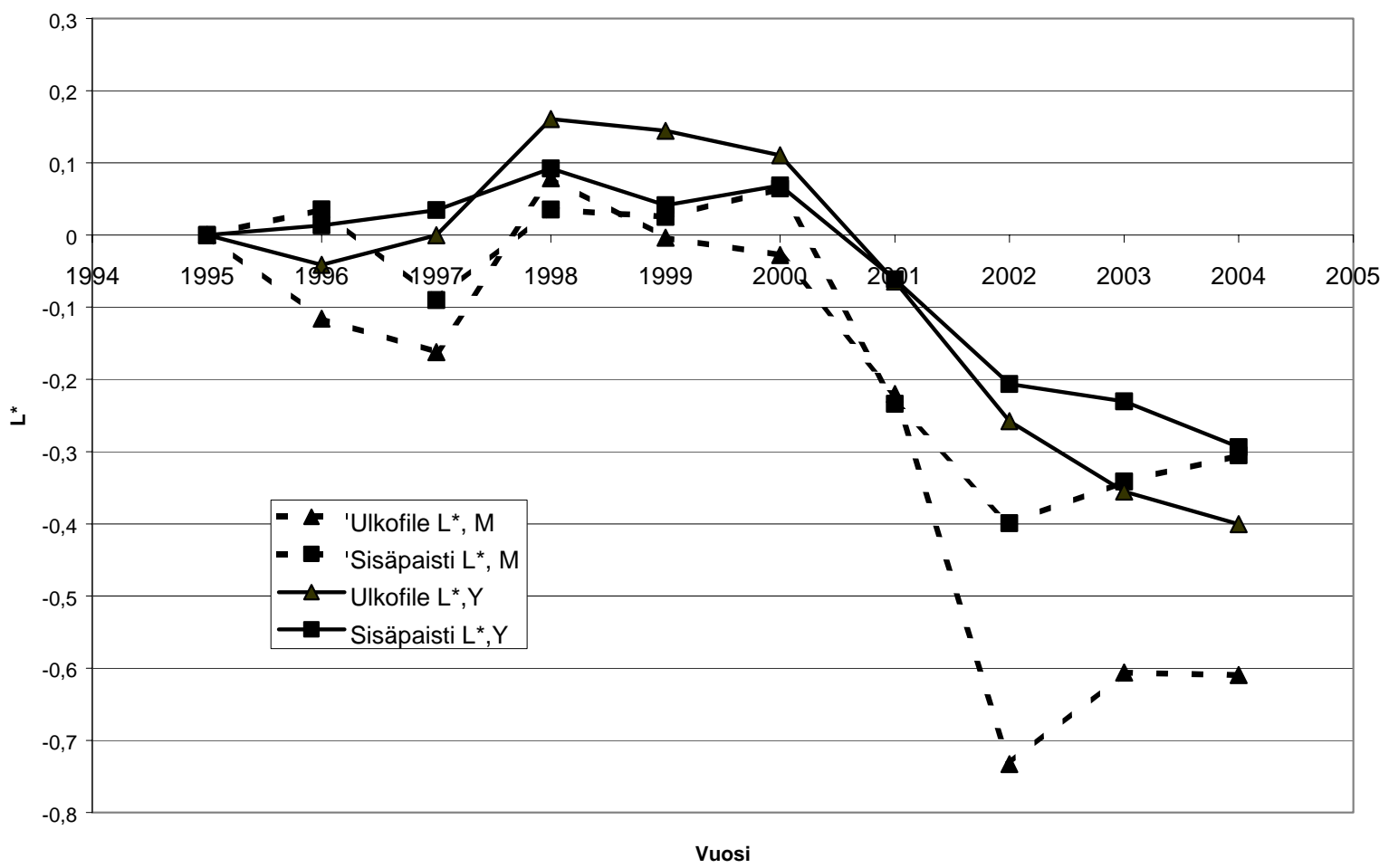

Kuvio 2. Ulkofileen ja sisäpaistin vaaleuden eli L*-arvojen geneettinen muutos vuodesta 1995 maatiais- ja yorkshiresioilla. 


\section{Johtopäätökset}

Kyljysselän ja sisäpaistin lihanlaatumittojen korrelaatiot olivat korkeita, mutta kuitenkin selvästi alle yhden, eli pelkän kyljysselän sisällyttäminen valintaohjelmaan ei takaa hyvää kinkun laatua, vaan laatu pitää mitata myös kinkusta. Johtuen epäsuotuisasta korrelaatiosta taloudellisesti tärkeiden lihaprosentin ja lihan laadun välillä, on lihan laatu säilytettävä jalostustavoitteissa, jotta lihan laatua voidaan parantaa tai laadun heikkenemistä ehkäistä liha-\% valittaessa. Punaisuudella (a*) on muita laatuominaisuuksia korkeampi periytymisaste. Koska se on lisäksi geneettisesti korreloitunut vaaleuden $\left(\mathrm{L}^{*}\right)$ kanssa, sen sisällyttäminen arvostelulaskentaan parantaa laadun arvosteluvarmuutta. Tässä tutkimuksessa estimoituja perinnöllisiä tunnuslukuja käytetään hyväksi kansallisessa sikojen jalostusarvojen laskennassa. Laatuominaisuuksien geneettiset trendit osoittavat, että lihan laatua voidaan valinnalla onnistuneesti parantaa.

\section{Kirjallisuus}

Andersen S. \& Pedersen, B. 1999. Genetic parameters for colour traits and $\mathrm{pH}$ correlation to production traits. In: Wenk, C. et. al. Eds. Quality of meat and fat in pigs as affected by genetics and nutrition. EAAP Publication No. 100. Wageningen Pers 200. p. 123-126.

CIE 1971 Colorimetry: Official recommendations of the International Commission of Illumination. Publication CIE No. 15. (E-1.3.1.) Paris, France. Bureau Central de la CIE.

Hovenier, R., Kanis, E., Brascamp, E.W. \& Knapp, P.W. 1995. Including meat quality in breeding programs. In: S

Joo, S.-T., Kauffman, R.G., Kim, B.-C. \& Kim, C.-J. 1995. The relationship between color and water-holding capasity in post rigor porcine longissimus muscle. Journal of Muscle Foods 6: $211-226$.

Kauffman, R.G., Sybesma, W., Smulders, F.J.M, Eikelenboom, G., Engel, B., van Laack, R.L.J.M., Hoving-Bolink, A.H., Sterrenburg, P., Nordheim, E.V., Walstra, P., \& van der Wal, P.G. 1993. The effectiveness of examining early post-mortem muscularity to predict ultimate pork quality. Meat Science 34: 283-300.

Knapp, P., William, A. \& Sölkner, J. 1997. Genetic parameters for lean meat content and meat quality traits in different pig breeds. Livestock Production Science 52: 69 - 73.

Madsen, P. \& Jensen, J. 2000. A user's guide to DMU. A package for analysing multivariate mixed models. Danish Institute of Agricultural Science, Tjele. 